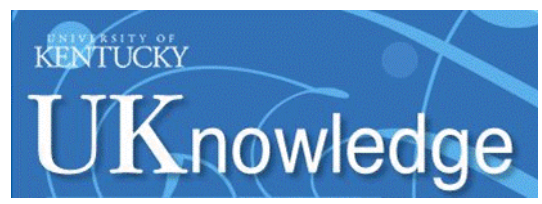

University of Kentucky

UKnowledge

$11-1-2016$

\title{
A Network Analysis of Developmental Change in ADHD Symptom Structure from Preschool to Adulthood
}

\author{
Michelle M. Martel \\ University of Kentucky, michelle.martel@uky.edu \\ Cheri A. Levinson \\ Washington University in St. Louis \\ Julia K. Langer \\ Washington University in St. Louis \\ Joel T. Nigg \\ Oregon Health \& Science University
}

Follow this and additional works at: https://uknowledge.uky.edu/psychology_facpub

Part of the Developmental Psychology Commons

Right click to open a feedback form in a new tab to let us know how this document benefits you.

\section{Repository Citation}

Martel, Michelle M.; Levinson, Cheri A.; Langer, Julia K.; and Nigg, Joel T., "A Network Analysis of Developmental Change in ADHD Symptom Structure from Preschool to Adulthood" (2016). Psychology Faculty Publications. 162.

https://uknowledge.uky.edu/psychology_facpub/162

This Article is brought to you for free and open access by the Psychology at UKnowledge. It has been accepted for inclusion in Psychology Faculty Publications by an authorized administrator of UKnowledge. For more information, please contact UKnowledge@lsv.uky.edu. 


\section{A Network Analysis of Developmental Change in ADHD Symptom Structure from Preschool to Adulthood}

Digital Object Identifier (DOI)

https://doi.org/10.1177/2167702615618664

Notes/Citation Information

Published in Clinical Psychological Science, v. 4, issue 6, p. 988-1001.

Michelle M. Martel, Cheri A. Levinson, Julia K. Langer, and Joel T. Nigg, A Network Analysis of Developmental Change in ADHD Symptom Structure from Preschool to Adulthood, Clinical Psychological Science 4(6) pp. 988-1001. Copyright @ 2016 The Author(s). DOI: https://doi.org/10.1177/ 2167702615618664

The copyright holder has granted the permission for posting the article here.

The document available for download is the authors' post-peer-review final draft of the article. 


\title{
A network analysis of developmental change in ADHD symptom structure from preschool to adulthood
}

\author{
Michelle M. Martel, \\ Psychology Department, University of Kentucky \\ Cheri A. Levinson, \\ Department of Psychiatry, Washington University in St. Louis \\ Julia K. Langer, and \\ Department of Psychology, Washington University in St. Louis \\ Joel T. Nigg \\ Psychiatry Department, Oregon Health \& Science University
}

\begin{abstract}
Although there is substantial support for the validity of the diagnosis of ADHD, there is considerable disagreement about how to best capture developmental changes in the expression of ADHD symptomatology. The current paper examines the associations among the 18 individual ADHD symptoms using a novel network analysis approach, from preschool to adulthood. The 1,420 participants were grouped into four age brackets: Preschool (age 3-6, $n=109$ ), childhood (age 6-12, $n=548$ ), adolescence (age 13-17, $n=357$ ), and young adulthood (age 18-36, $n=$ 406). All participants completed a multi-stage, multi-informant diagnostic process, and self and informant symptom ratings were obtained. Network analysis indicated ADHD symptom structure became more differentiated over development. Two symptoms Often easily distracted and Difficulty sustaining attention appeared as central, or core, symptoms across all age groups. Thus, a small number of core symptoms may warrant extra weighting in future diagnostic systems.
\end{abstract}

\section{Keywords}

Attention; developmental disorders; developmental psychopathology

\begin{abstract}
Attention-Deficit/Hyperactivity Disorder (ADHD) is a behavioral disorder operationally defined by nine symptoms labeled as inattentive, six symptoms labeled as hyperactive, and three symptoms labeled as impulsive, for a total of 18 ADHD symptoms (APA, 2013). Hyperactive and impulsive symptoms are combined into a single hyperactive-impulsive dimension based on factor analyses that suggested a two-factor solution on combined childadolescent samples fit nearly as well as a less-parsimonious three-factor solution (Lahey et al., 1994). As with other DSM-diagnoses, diagnosis requires a count of equally-weighted items. In the case of ADHD, symptoms are counted separately within the inattentive and
\end{abstract}


hyperactive-impulsive symptom domains; a total of six or more in either category meets diagnostic threshold. Since DSM-III, heterogeneity of clinical presentation among individuals with ADHD has been referenced by use of subtypes (termed presentations in DSM-5) which, in DSM-IV and DSM-5, depend on the symptom domain from which an individual's symptoms primarily reside: predominantly inattentive, predominantly hyperactive-impulsive, or combined (i.e., both; APA, 2013). Although historically ADHD was considered a childhood disorder, since DSM-5, it is considered a neurodevelopmental condition with childhood onset apparent as early as $3-4$ years of age that can persist, and therefore be diagnosed, in adulthood (reviewed by Faraone et al., 2000). With growing recognition of the clinical importance of preschool and adult case identification and treatment, the need has grown more acute for clarification as to how well current ADHD symptoms capture the construct across each of these different developmental periods.

ADHD symptoms exhibit important normative change with development. During preschool, hyperactivity peaks, is salient, and is the most common ADHD symptom manifestation, and then normatively declines throughout the remainder of childhood (Olson, 2002). In contrast, inattentive symptoms increase during childhood, become more noticeable as children enter school, and remain relatively more stable over time (Hart et al., 1995). These normative changes in symptoms are in line with prevalence rates of ADHD which peak around 5-6\% during preschool and childhood (Egger \& Angold, 2006; Polyanczyk et al., 2007) and then decline slightly during adulthood to around 3-4\% with approximately half of childhood cases continuing into adulthood (Kessler et al., 2006).

In line with DSM-5 two-domain criteria and developmental change over time, confirmatory factor analyses in clinical and population samples of children have tended to support a two(i.e., inattention vs. hyperactivity-impulsivity) or occasionally three- (i.e., inattention, hyperactivity, impulsivity) factor structure of ADHD (Amador-Campos et al., 2005; Amador-Campos et al., 2006; Bauermeister et al., 1992; 1995; Burns et al., 1997a; 1997b; 2001; DuPaul et al., 1997; Gomez et al., 2005; Lahey et al., 1988; Pillow et al., 1998; Wolraich et al., 2003). More recently, bifactor, or hierarchical, models of ADHD with a general "g" ADHD factor co-existing with "s" specific factors of inattention and hyperactivity-impulsivity or inattention, hyperactivity, and impulsivity have received support in children and adolescents (Martel et al., 2010; Toplak et al., 2009). Yet, comparatively few studies on the factor structure of ADHD exist in preschoolers or adults. Studies on preschoolers have found either equivocal results (Hardy et al., 2007) or have supported a one-factor ADHD model (Willoughby et al., 2012). In adults, one study found support for a three-factor model of inattention, hyperactivity, and impulsivity in a nonclinical sample not fully evaluated for presence of DSM ADHD criteria (Span, Earleywine, \& Strybel, 2002). A second study comparing children and adults with ADHD found that a similar bifactor structure of "g" ADHD and "s" inattention and hyperactivity-impulsivity fit similarly in children and adults with ADHD (Martel et al., 2012). Yet, the hyperactivity-impulsivity factor loadings were significantly different in children and adults, particularly for the symptoms of Fidgets; Leaves seat; Runs/climbs; Talks a lot; Blurts, and Interrupts, intrudes. Further, Fidgets; Leaves seat; Runs, climbs; and Driven by a motor exhibited non-significant loadings on the "s" hyperactivity-impulsivity factor, suggesting that they are less important in adults than in children. 
These observations are consistent with idea that current ADHD criteria, originally developed for children and adolescents (Lahey, 1994), may not be sensitive to adult ADHD symptom manifestation (Kessler et al., 2006). DSM-5 attempts to address this issue by proposing a slight reduction in the symptom cut point needed for adult diagnosis, lowering the symptom threshold from six to five in either the inattentive and hyperactive-impulsive symptom domains (APA, 2013). Yet, this does not address developmental change in the structure or form of symptom presentation. As described, very little empirical work has systemically compared ADHD symptom structure across key developmental periods from preschool to adulthood (see Amador-Campos et al., 2006; Martel et al., 2012 exceptions) or in the same study. The few studies that have attempted to examine this question are critically limited in that they have focused on higher-level latent factors, which may obscure important interrelations between individual symptoms. One way to address this is with network analysis of symptom structure.

Network analysis characterizes structures of a system, group, organization, or set in terms of nodes (herein, individual symptoms) and edges which connect the nodes (in this case, correlation coefficients; Borboom \& Cramer, 2013). Its focus on lower-level symptom interrelationships complements factor analytic work by providing examination of how particular symptoms interrelate with one another instead of their relationship to latent variables. Such information could suggest particular areas of difficulty (e.g., specific symptom constellations) faced by individuals with ADHD which might be useful assessment and intervention targets.

Network analysis also provides conceptually interesting quantitative and visual information about symptoms that are "core" or "central" to the overall network of symptoms. As an analogy, a switching station in an electrical grid has an outsized importance to the entire grid. In a social network, a leader may have relationships with all members that give that person outsized influence. In the case of symptoms, one symptom may relate to all others and have an outsized influence on their presentation. Thus, network analysis could identify symptoms that may be the most influential in producing or maintaining the disorder which may differ with development. If core symptoms could be identified across developmental periods, these could be emphasized in diagnosis across development to improve both diagnostic prediction and assessment as well as in research to improve etiological targets. Most fundamentally, that information would enable a better reflection in clinical practice of clinical reality.

Although the analysis is correlational, network analysis by design through directional coefficients suggests how individual nodes (symptoms) may causally relate to or influence one another. This is powerful for hypothesis generation. For example, network analysis might suggest that the ADHD symptom of Being easily distracted leads directly to the symptom Difficulties with sustained attention instead of ADHD being best viewed as a collection of co-occurring symptoms driven by an underlying construct, as in factor analysis (see Borsboom \& Cramer, 2013 for a detailed explanation on the benefits of network analysis over factor analysis). Of critical importance, this approach could begin to suggest hypotheses about how symptoms interrelate and develop over time, suggesting possible causal patterns between symptoms over time (Borsboom \& Cramer, 2013). Such 
information, if replicated using experimental designs, could suggest targeted interventions directed at particular symptoms or symptom clusters during particular developmental periods in future prospective work.

The current paper thus presents the first network analyses to assess ADHD symptoms across developmental periods that span preschool into adulthood. Such a network analytic approach allows for focused analysis of the relative importance of individual symptoms and their interrelation, enabling both (a) evaluation of changes in structure of these relationships within a common framework over time and (b) identification of core symptoms within the syndrome structure. Visualizations of the networks using one- (ADHD), two- (inattention and hyperactivity-impulsivity) and three- (inattention, hyperactivity, and impulsivity) clusters were planned. It was hypothesized that the symptom structure would move from relatively simple and undifferentiated to relatively complex and differentiated. Symptom centrality (i.e. how important symptoms are in the network) and bridge, or adjoining, symptoms were examined within developmental periods. It was hypothesized that core symptoms could be identified across development, within the differentiating pattern, facilitating assessment of ADHD across the lifespan.

\section{METHOD}

\section{Participants}

Overview-Preschoolers, children, adolescents, and adults, along with their parents, teachers, and significant others, participated in the current study. Participants were recruited from the community and completed a comparable multistage screening and diagnostic procedure including informed consent consistent with APA, NIH, and IRB guidelines.

Preschool sample: Preschool participants were 109 young children between the ages of three and six and their primary caregivers and identified teachers, daycare providers, or babysitters. Sixty-four percent of the sample was male, and 36\% of the sample identified as ethnic or racial minority. Annual family income exhibited a wide range (from below $\$ 20,000$ to over $\$ 100,000$ US dollars). Based on multistage and comprehensive diagnostic screening procedures (detailed below), children were classified into two groups: ADHD $(n=61)$ and typically developing non-ADHD children $(n=48)$. The non-ADHD group included children with subthreshold (i.e., 4 or 5) symptoms, consistent with research suggesting that ADHD may be better captured by continuous dimensions than categorical diagnosis (Haslam et al., 2006; Marcus \& Barry, 2011).

Child sample: There were 548 child participants (59\% male) between the ages of 6 and 12 and their primary caregivers and teachers. Fifty-nine percent were male, and $26 \%$ identified as ethnic or racial minority. Annual family income exhibited a wide range from below $\$ 20,000$ to over $\$ 500,000$ US dollars. Using DSM-IV-TR criteria, children were classified as ADHD ( $n=302)$ or typically developing non-ADHD comparison youth $(n=246)$, including subthreshold cases.

Adolescent sample: Adolescent sample participants were 357 youth between ages 13 and 17 and their primary caregivers and teachers. Fifty-nine percent were male, and 22\% 
identified themselves as ethnic or racial minorities. Families exhibited a wide range of incomes. Participants included those who met research criteria for ADHD, any subtype ( $n=$ $144)$, and typically developing non-ADHD youth $(n=213)$, including subthreshold cases.

Adult sample: Adult participants were 406 adults between the ages of 18 and 37 and identified parents, significant others, or friends. Forty-nine percent were male, and $13 \%$ identified as ethnic or racial minority. They were classified as ADHD $(n=145)$ and nonADHD comparison ( $n=261)$, including subthreshold cases.

Identification and Recruitment-All participants were recruited using a diverse set of recruitment strategies including radio, newspaper, and movie theater advertisements and general mailings or flyers targeting individuals who think they or their children might have attention problems and/or advertising a study of the development of attention, as well as mailings to local clinics (although less than $10 \%$ of the sample came from clinic advertisements), in order to recruit a representative sample of community volunteers enriched for presence of ADHD symptoms. Prospective participants then underwent a standard multi-gate screening process to identify cases and non-cases eligible for the study. At stage 1, participants (or parents of participants) completed a telephone screen to assess eligibility. To be eligible to participate in the study, participants were required to be a native English speaker and not have a sensorimotor disability, neurological illness, or be on a current prescription for antidepressant, antipsychotic, or anticonvulsant medication. These eligibility criteria were chosen to ensure study participants could adequately understand task instructions and to eliminate the confounds of comorbid conditions and medication use that could affect cognitive performance. Participants who passed this stage of screening went on to a second stage of screening.

At stage 2, eligible participants and their parent and teachers (for children) or significant others (for adults) completed semi-structured interviews and standardized normative rating scales, described below, to ascertain ADHD and comorbid psychopathology. For the preschool, child, and adolescence samples, parents of child participants completed either the Diagnostic Interview Schedule for Children (DISC-IV; Shaffer, Fisher, Lucas, Dulcan, \& Schwab-Stone, 2000), the Kiddie Schedule for Affective Disorders and Schizophrenia (KSADS-E; Puig-Antich \& Ryan, 1986), or the Kiddie Disruptive Behavior Disorders Schedule (K-DBDS: Leblanc et al., 2008). In addition, parents and teachers completed the following standardized rating scales: Child Behavior Checklist/Teacher Report Form (CBCL/TRF; Achenbach, 1991a) and the ADHD Rating Scale (ADHD-RS; DuPaul et al., 1998).

For the adult sample, participants completed a retrospective Kiddie Schedule for Affective Disorders and Schizophrenia (KSADS-E; Puig-Antich \& Ryan, 1986) in order to assess current and past ADHD symptoms. Adult participants also completed the Barkley and Murphy (1998) Current ADHD Symptoms Rating Scale, the Conners, Erhardt, and Sparrow (1999) Adult ADHD Rating Scale, the Achenbach (1991b) Young Adult Self Report, and the Brown (1996) Adult ADHD Rating Scale. Two other informants also reported on the adult participant's ADHD symptoms. One informant (usually a parent) reported on childhood ADHD symptoms via a retrospective K-SADS ADHD module and the ADHD Rating Scale, 
and another informant (usually a partner or friend) completed a current K-SADS ADHD module and the Conners peer rating, the Barkley and Murphy peer ratings on adult symptoms, and a brief screen of antisocial behavior and drug and alcohol use.

For all participants, a clinical diagnostician then used this information to arrive at a "best estimate" diagnosis (Faraone, 2000). Inter-rater agreement was satisfactory on presence or absence of ADHD ( $\kappa \geq .80)$ and ADHD subtype ( $\kappa$ ranged from .74 to .89).

\section{Measures}

ADHD Symptoms-The 18 ADHD symptoms were coded on a 0 (rarely or never) to 3 (always or very often) rating scale on the ADHD Rating Scale (Barkley \& Murphy, 1998; DuPaul et al., 1998) using parent report for preschoolers, children, and adolescents. For adults, other report was also utilized which was mostly parent report, but also included significant other, friend, and employer report. Secondary analyses examined reporter effects by examining differences in networks between parent report and teacher report in children and between other (mostly parent) and self report in adults.

\section{Data Analytic Plan}

We used network analysis to examine a network of ADHD symptoms and identify potential core ADHD symptoms. In a network analysis, symptoms are assumed to be correlated with each other and represent a complex network of psychopathology. This type of analysis allows for examination of interplay between symptoms and allows for tests of which symptoms might be central to the network. The more central a symptom is to the center of the network, the more strongly it is related to many of the other symptoms in the network and the more involved it is in many of the pathways within the network. This methodology differs from Item Response Theory (IRT) and Factor Analysis in several ways. Instead of identifying an underlying latent variable as in factor analysis, or identifying specific items that contain response bias as in IRT, network analysis focuses on item interrelations and thereby suggests hypotheses about which symptoms themselves may be causal players in the symptom network. For example, instead of assuming that major depression stems from an underlying latent variable consisting of items such as sleep problems, fatigue, and low mood, network analysis assumes that these symptoms might be intertwined in a causal system not stemming from a latent variable. Such a system might suggest that sleep problems cause fatigue, which causes low mood, instead of each of these symptoms loading onto a major depression latent variable. For more information on theory behind network analysis and empirical examples of how to conduct network analysis, please see Borsboom and Cramer (2013).

A series of networks were computed using the R package qgraph (Epskamp, Cramer, Waldorp, Schmittmann, \& Borsboom, 2012). We used the portion of the script and followed procedures provided in the supplemental materials from Borsboom and Cramer (2013). Networks were not specified to be directional, nor did we set a predetermined number of paths or strength of correlations. For each age group (i.e., preschool, childhood, adolescence, and adulthood), networks were computed and then visualized in three different ways using different colors as one-cluster (ADHD), two-cluster (inattention and hyperactivity- 
impulsivity), and three-cluster (inattention, hyperactivity, and impulsivity). The three network visualizations within an age group were the same, and -- for parsimony-- the bestfitting network visualization within each age range is shown in the relevant figures, visualized with one, two, or three colors, based on how symptoms clustered together. Within each of the modeled networks, nodes represent individual symptoms (e.g., one rated item on the ADHD Rating Scale), and edges represent the relationship or distance between these individual symptoms (in this case, the correlation coefficient).

First, networks were visually inspected through examination of tight clustering of individual symptoms and potential bridge symptoms. Bridge nodes are symptoms that link adjacent symptoms together and are theorized to constitute pathways that could causally connect symptoms or behaviors (pending longitudinal data analysis). Next, statistical indices, called measures of centrality, were calculated to quantify aspects of the network, particularly node centrality, using the tnet package in R (Freeman, 1979; Opsahl, Agneessens, \& Skvoretz, 2010). We used two indices of centrality: Closeness and Degree. Closeness represents the inverse of the sum of distance to all other nodes; higher numbers indicating that a node is more central to the network relative to the other items. Degree represents the sum of the weights of the relations with which a node is involved and captures the strength of the relations that a node has with all other nodes (Opsahl \& Panzarasa, 2009). Again, higher numbers indicate higher centrality.

\section{RESULTS}

\section{Preschool Network}

During preschool, as shown visually in Figure 1, the nodes formed a tight cluster suggesting that symptoms could be construed as one single clustered network visualized as ADHD. As seen in Figure 1, a network of six core symptoms is at the center of the network: Often easily distracted; Often does not follow through and fails to finish; Unable to play quietly, Does not seem to listen; Difficulty organizing, and Difficulty sustaining attention. In particular, Often easily distracted is linked with Does not listen, Difficulty sustaining attention, and Does not follow through and fails to finish. In addition, Often forgetful and Often loses things were linked. Difficulty waiting turn, Unable to play or engage in leisure activities quietly, and Often interrupts or intrudes appear to be a linked set of impulsive symptoms in this age range. Finally, Runs about or climbs, Leaves seat in situations where remaining seated in expected, and Often "on the go," acts as if "driven by a motor" are a linked set of motor symptoms in this age range. There are also two symptoms that are less important and less central to network: Fails to pay close attention and makes careless mistakes and Often blurts out answer. These findings are supported by the indices of centrality shown in Supplemental Appendix A, which shows that the symptoms central to the network have higher closeness and degree values (closeness $\geq .06$; degree $\geq 9.87$ ), whereas those on the edges of the network have lower values (closeness $\leq .054$; degree $\leq$ $8.05)$. 


\section{Childhood Networks}

During childhood, from visual inspection, two clusters are best supported: inattention and hyperactivity-impulsivity. As shown visually in Figure 2, inattention forms a tight network, while hyperactivity-impulsivity is more widely dispersed in a separate cluster. Does not follow through, fails to finish is the central inattentive symptom. Does not seem to listen, a central symptom during preschool, is the symptom that bridges the inattentive and hyperactive-impulsive clusters, leading to Often easily distracted (a central symptom during preschool), Difficulty waiting turn and Interrupts, intrudes on others. Talks excessively is highly linked with impulsive symptoms, as in ICD-10 criteria. Difficulty sustaining attention is highly linked with Often fidgets. Similar to preschool results, Runs about or climbs, Leaves seat in situations where remaining seated in expected, and Often "on the go," acts as if "driven by a motor" are a linked set of motor symptoms in this age range, also highly linked with Often fidgets and Often unable to play or engage in leisure activities quietly, the latter of which link these hyperactive symptoms to impulsive symptoms to form a cluster. Indices of centrality, shown in Supplemental Appendix A, suggest that Difficulty sustaining attention and Often easily distracted are central to ADHD symptoms in this age range, as indicated by closeness of .062 and degree of 10.05 or above, while Often runs about or climbs and Often talks excessively are less central to the network (closeness of .054 or below; degree of 7.54 or below).

\section{Adolescent Networks}

During adolescence, three clusters are best supported visually: inattention, hyperactivity, and impulsivity, shown in Figure 3. Inattention and impulsivity form a tight network, and the hyperactivity items are less central, particularly Often unable to play or engage in leisure activities quietly. In this age range, impulsivity symptoms are more central, appearing in the middle of the cluster. Further, there is a verbal impulsivity triad with the symptoms Often talks excessively, Often unable to play or engage in leisure activities quietly, and Often interrupts or intrudes tightly linked. Often easily distracted, a central symptom during preschool and a bridge symptom during childhood, is the symptom bridging inattentive and impulsive items (with the highest closeness of .063, degree of 10.23). Often reluctant to engage in tasks that require sustained mental effort is the central inattentive symptom. In contrast to preschool and childhood, Often does not seem to listen is less connected to the network and seemingly not as important. Measure of centrality shown in Figure 3 indicate that Often runs about or climbs, Often "on the go," acting as if "driven by a motor," and Often talks excessively are also much less central in this age range (closeness of .054 or below; degree of 7.47 or below).

\section{Adult Networks}

During adulthood, three clusters were best supported, shown visually in Figure 4. Similar to the adolescent network, but even more notably, the third cluster might best be termed a verbal impulsivity cluster due to tight linkages between Often interrupts or intrudes, Often blurts out an answer, Often talks excessively, and Often unable to play or engage in leisure activities quietly. As in all age ranges, and as indexed by measures of centrality in Supplemental Appendix A, Often easily distracted and Difficulty sustaining attention are 
central symptoms with closeness of .066 and degree of 7.53 or above. As in childhood and adolescence, Often easily distracted is a bridge symptom between inattention, hyperactivity, and impulsivity. However, compared to the other age ranges, inattentive symptoms are less tightly clustered in adulthood. Difficulty sustaining attention, Reluctant to engage in tasks that require sustained mental effort, and Often easily distracted form a tight triad of inattentive/mental effort symptoms in the middle of the ADHD cluster. Runs about or climbs, Leaves seat in situations where remaining seated in expected, and Often fidgets remain a central motor symptom triad in this age range, similar to during preschool and childhood. Often forgetful, Difficulty organizing tasks and activities, and Often loses things form a triad of inattentive-disorganized symptoms less central to the ADHD cluster. Often does not seem to listen and Talks excessively are less central to the network and are less central symptoms in this age range (closeness of .052 and degree of 5.08 or below).

\section{Secondary Checks Based on Informant Report}

Childhood results largely held using teacher (vs. parent) report of child symptoms, as visualized in Supplemental Appendix B. Adult results varied based on reporter. A onecluster solution seemed best based on self report ratings, as compared to peer report ratings, as visualized in Supplemental Appendix C.

\section{DISCUSSION}

Overall, study results suggested that ADHD symptoms become more differentiated (mathematically, less tightly clustered) across development. During preschool, all symptoms clustered tightly together. However, as expected, and consistent with an extensive factor analytic literature, network analysis confirmed that the DSM-5 two-domain symptom structure is most appropriate during childhood. Impulsive symptoms became more central and important during adolescence. During adulthood, symptoms became most differentiated, clustering into mental effort, disorganization, motor overactivity, and verbal impulsivity clusters. Yet, continuity was also apparent. Across developmental periods, Often easily distracted was an important bridge symptom between inattentive and hyperactive-impulsive symptom domains regardless of developmental period, suggesting that the presence of this symptom may increase risk for high symptom counts in both symptom domains. Further, Often easily distracted and Difficulty sustaining attention seem to be central, or core, symptoms, suggesting that they may exert a high level of influence on the manifestation of other ADHD symptoms.

These findings are informative in several respects. Progressive differentiation of symptoms as individuals' age suggests that -- during preschool-- children with ADHD may exhibit similar difficulties with all symptoms. However, by adulthood, distinct clusters of cooccurring symptoms are apparent, perhaps based on individual patterns of coping and skills (Casey et al., 2008; Sterba et al., 2010). This finding corresponds with prior work suggesting that individuals with ADHD may be neurobiologically immature, exhibiting high levels of ADHD symptoms across the board during preschool and only "catching up" to typicallydeveloping individuals (at least in some instances) in regard to cortical development during late adolescence or early adulthood (Shaw et al., 2007).

Clin Psychol Sci. Author manuscript; available in PMC 2017 November 01. 
While motor difficulties and clusters are apparent early during development, as early as preschool, impulsivity, particularly verbal impulsivity, including the symptom of Talks excessively as in the ICD-10 criteria, appear to become more salient during childhood. Impulsivity is particularly central to the ADHD network during adolescence, a period of time in which the limbic system in especially powerful given the relative underdevelopment of the prefrontal cortex (Casey et al., 2008). Further, adolescents experience more freedom than younger children, making their impulsive decisions more noticeable. Impulsivity may thus drive other ADHD symptoms and, speculatively, other comorbid problems during this period. Verbal impulsivity is then particularly important during adulthood, perhaps because it is the last aspect of impulsivity to be reined under voluntary control. Thus, impulsivity may be an important dimensional, transdiagnostic core construct that could benefit from efficient screening and assessment, in line with NIMH RDoC initiatives (Insel, 2014).

During adulthood, meaningful low mental effort, disorganization, motor overactivity, and verbal impulsivity clusters of symptoms were apparent. By the time individuals with ADHD reach adulthood, their symptoms may be more ingrained and falling into consistent, mutually-reinforcing patterns. That is, a history of being Often easily distracted may lead Difficulty sustaining attention and in turn may lead to a more habitual behavior of Reluctance to engage in tasks that require sustained mental effort, the low mental effort triad. Likewise, being Often forgetful and Often loses things may cause an adult with ADHD to have Difficulty organizing tasks and activities, the disorganized triad. Often blurts out an answer before a question has been completed is likely highly associated with Often interrupts, as well as Often having difficulty waiting his or her turn, the verbal impulsivity triad.

Importantly, self report of ADHD symptoms in adulthood was dramatically different than other (mostly parent) report of symptoms, and this finding was in contrast to parent and teacher report of childhood ADHD symptoms, which looked similar to one another. This finding might suggest that adults with ADHD, similar to children with ADHD, are not accurate reporters of their own symptoms (Knouse et al., 2005; Kooij et al., 2008; Owens et al., 2007). Thus, it may be beneficial to emphasize other informant reports of ADHD symptoms during adolescence and adulthood (Molina \& Sibley, 2014; Sibley et al., 2012), similar to what is recommended in children (Pelham et al., 2005). Alternatively, this finding might suggest that self and others think of or observe ADHD symptoms in different ways (De Los Reyes \& Kazdin, 2005).

One of our primary findings is that there are two central symptoms across developmental periods. Specifically, Often easily distracted and Difficulty sustaining attention are central symptoms across age ranges. Thus, these symptoms may represent the core of ADHD, regardless of developmental period. Therefore, these symptoms may be usefully emphasized across age ranges and, with further revisions of the DSM, might be useful as weighted symptoms or core symptoms utilized across developmental periods. Currently, they could be useful as screening items to identify individuals across age ranges who are more likely to meet diagnostic criteria for ADHD. Theoretically, these core symptoms may be the behaviors maintaining the disorder by causing other symptoms to develop or reinforcing other symptoms. Further, Often easily distracted is a symptom that bridges across the 
inattentive and hyperactive-impulsive symptom domain across most age ranges, suggesting that Often easily distracted may be a marker of more severe ADHD symptom profiles cutting across inattentive and hyperactive-impulsive symptom domains and, when present, may increase the likelihood that a given individual will have problems with both inattention and hyperactivity-impulsivity. Therefore, these core symptoms, particularly distraction, might be key treatment targets. Intervening on these symptoms may be the most efficient treatment for ADHD given that changes to these symptoms likely to project to the ADHD network as a whole.

Of course, conclusions are limited by the fact that the current study utilized cross-sectional samples of preschoolers, children, adolescents, and young adults. Results should also be replicated using longitudinal data. Such an approach could also be useful for mapping an individual's specific causal network of ADHD symptoms to perfect understanding of ADHD clinical heterogeneity and personalize intervention approaches to the individual. In addition, the current study was limited by its correlational design so we are unable to make causal conclusions about direction of effects between symptoms or in regard to the direction and nature of influences from neurobiology, the environment, and child symptoms. Future work should experimentally test causal pathways between symptoms and the utility of intervening on core symptoms. For example, if Often easily distracted and Difficulty sustaining attention are early-emerging core symptoms, then behavioral intervention using reward charts to facilitate improvements in distraction and sustained attention should lead to downstream improvements in other ADHD symptoms and remission in ADHD (and possibly other comorbid) symptoms over development. Such a study would advance causal theories of ADHD by suggesting inter-individual pathways between symptoms and perhaps refined etiological factors for clusters of symptoms. Finally, we are limited by the current capabilities of network analysis, such as having no current clear guidelines on the strength of indices of centrality. Further, since network analysis relies on single items represented as symptoms, it is difficult to infer the reliability of item responses without obtaining multiple responses on the same item for each participant. We hope that future methodological work will provide more insight and even greater utility of such analysis.

Particularly important next studies include testing the utility of screening general population samples for ADHD using a few core symptoms of Often easily distracted and Difficulty sustaining attention in comparison to the full 18 symptoms (e.g., Kessler et al., 2006). Such a stream-lined assessment screening process, if successful, would save pediatricians or other practitioners significant time without requiring a change in symptom lists and could be useful in population screening. Emphasis on these core symptoms in diagnostic assessment procedures should be validated through testing prediction of external criteria such as academic achievement, impairment, comorbid problems, and in comparison to full ADHD diagnostic criteria.

\section{Supplementary Material}

Refer to Web version on PubMed Central for supplementary material. 


\section{Acknowledgments}

We are indebted to the study participants and staff who made this study possible. This research was supported by NIH National Institute of Mental Health Grant R01-MH63146 and MH3759105 to Joel Nigg and 5R03 HD062599-02 and K12 DA 035150 to Michelle Martel.

\section{References}

Achenbach, T. Manual for the Child Behavior Checklist/4-18 and 1991 Profile. Burlington, VT: University of Vermont Department of Psychiatry; 1991a.

Achenbach, T. Manual for the Young Adult Self Report and Young Adult Behavior Checklist. Burlington: University of Vermont, Department of Psychiatry; 1991b.

Amador-Campos JA, Forns-Santacana M, Martorell-Balanzo B, Guardia-Olmos J, Pero-Cebollero M. Confirmatory factor analysis of parents' and teachers' ratings of DSM-IV symptoms of attention deficit hyperactivity disorder in a Spanish sample. Psychological Reports. 2005; 97(3):847-860. [PubMed: 16512303]

Amador-Campos JA, Forns-Santacana M, Martorell-Balanzo B, Guardia-Olmos J, Pero-Cebollero M. DSM-IV Attention Deficit Hyperactivity Disorder symptoms: Agreement between informants in prevalence and factor structure at different ages. Journal of Psychopathology and Behavioral Assessment. 2006; 28(1):23-32.

American Psychiatric Association. Diagnostic and Statistical Manual of Mental Disorders. 5th ed.. Washington, D.C.: American Psychiatric Association; 2013.

Barkley, RA.; Murphy, KR. Attention-deficit hyperactivity disorder: A clinical workbook. 2nd Ed.. New York: Guilford Press; 1998.

Bauermeister JJ, Alegria M, Bird HR, Rubio-Stipec M, et al. Are attentional-hyperactivity deficits unidimensioanl or multidimensional syndromes? Empircal findings from a community sample. Journal of the American Academy of Child and Adolescent Psychiatry. 1992; 31(3):423-431. [PubMed: 1592773]

Bauermeister JJ, Bird HR, Canino G, Rubio-Stipec M, et al. Dimensions of attention deficit hyperactivity disorder: Findings from teacher and parent reports in a community sample. Journal of Clinical Child Psychology. 1995; 24(3):264-271.

Borsboom D, Cramer AOJ. Network analysis: An integrative approach to the structure of psychopathology. Annual Review of Clinical Psychology. 2013; 9:91-121.

Brown, TE. Brown Attention-Deficit Disorder Scales. San Antonio, TX: Psychological Corporation; 1996.

Burns GL, Boe B, Walsh JA, Sommers-Flanagan R, Teegarden LA. A confirmatory factor analysis on the DSM-IV ADHD and ODD symptoms: What is the best model for the organization of these symptoms? Journal of Abnormal Child Psychology. 2001; 29(4):339-349. [PubMed: 11523839]

Burns GL, Walsh JA, Owen SM, Snell J. Internal validity of Attention Deficit Hyperactivity Disorder, Oppositional Defiant Disorder, and overt Conduct Disorder symptoms in young children: Implications from teacher ratings for a dimensional approach to symptom validity. Journal of Clinical Child Psychology. 1997a; 26(3):266-275. [PubMed: 9292384]

Burns GL, Walsh JA, Patterson DR, Holte CS, Sommers-Flanagan R, Parker CM. Internal validity of the disruptive behavior disorder symptoms: Implications from parent ratings for a dimensional approach to symptom validity. Journal of Abnormal Child Psychology. 1997b; 25(4):307-319. [PubMed: 9304447]

Casey BJ, Jones RM, Hare TA. The adolescent brain. Annals of the New York Academy of Sciences. 2008; 1124(1):111-126. [PubMed: 18400927]

Conners, CK. Conners Rating Scales-Revised. Toronto: Multi-Health Systems, Inc; 1997.

Conners, CK.; Erhardt, D.; Sparrow, E. Adult ADHD Rating Scales: Technical manual. Toronto, Ontario, Canada: Multi-Health Systems; 1999.

De Los Reyes A, Kazdin AE. Informant discrepancies in the assessment of childhood psychopathology: a critical review, theoretical framework, and recommendations for further study. Psychological bulletin. 2005; 131(4):483. [PubMed: 16060799]

Clin Psychol Sci. Author manuscript; available in PMC 2017 November 01. 
DuPaul, GJ.; Power, TJ.; Anastopolous, AD.; Reid, R. ADHD Rating Scale_IV: Checklists, Norms, \& Clinical Interpretation. New York: Guilford Press; 1998.

DuPaul GJ, Power TJ, Anastopoulos AD, Reid R, McGoey KE, Ikeda MJ. Teacher ratings of Attention Deficit Hyperactivity Disorder symptoms: Factor structure and normative data. Psychological Assessment. 1997; 9(4):436-444.

Egger HL, Angold A. Common emotional and behavioral disorders in preschool children: Presentation, nosology, and epidemiology. Journal of Child Psychology and Psychiatry. 2006; 47(3/4):313-337. [PubMed: 16492262]

Epskamp S, Cramer AOJ, Waldorp LJ, Schmittman VD, Borsboom D. Qgraph: Network visualizations of relationships in psychometric data. Journal of Statistical Software. 2012; 48(4):1-18.

Faraone SV. Attention Deficit Hyperactivity Disorder in adults: Implications for theory of diagnosis. Current Directions in Psychological Science. 2000; 9(1):33-36.

Freeman LC. Centrality in social networks conceptual clarification. Social Networks. 1979; 1(3):215239.

Gomez R, Burns GL, Walsh JA, Hafetz N. A multitrait-multisource confirmatory factor analytic approach to the construct validity of ADHD and ODD Rating Scales with Malaysian children. Journal of Abnormal Child Psychology. 2005; 33(2):241-254. [PubMed: 15839501]

Hardy KK, Kollins SH, Murray DW, Riddle MA, Greenhill L, Cunningham C, Chuang SZ. Factor structure of parent-and teacher-rated attention-deficit/hyperactivity disorder symptoms in the Preschoolers with Attention-Deficit/Hyperactivity Disorder Treatment Study (PATS). Journal of child and adolescent psychopharmacology. 2007; 17(5):621-633. [PubMed: 17979582]

Hart EL, Lahey BB, Loeber R, Applegate B, Frick PJ. Developmental change in attention-deficit hyperactivity disorder in boys: a four-year longitudinal study. Journal of abnormal child psychology. 1995; 23(6):729-749. [PubMed: 8609310]

Haslam N, Williams B, Prior M, Haslam R, Graetz B, Sawyer M. The latent structure of attentiondeficit/hyperactivity disorder: a taxometric analysis. Australian and New Zealand Journal of Psychiatry. 2006; 40(8):639-647. [PubMed: 16866759]

Insel TR. The NIMH research domain criteria (RDoC) project: precision medicine for psychiatry. American Journal of Psychiatry. 2014; 171(4):395-397. [PubMed: 24687194]

Kessler RC, Adler L, Barkley R, Biederman J, Conners CK, Demler O, Zaslavsky AM. The prevalence and correlates of adult ADHD in the United States: results from the National Comorbidity Survey Replication. The American journal of psychiatry. 2006; 163(4):716-723. [PubMed: 16585449]

Knouse LE, Bagwell CL, Barkley RA, Murphy KR. Accuracy of self-evaluation in adults with ADHD evidence from a driving study. Journal of Attention Disorders. 2005; 8(4):221-234. [PubMed: 16110052]

Kooij JS, Boonstra AM, Swinkels SHN, Bekker EM, de Noord I, Buitelaar JK. Reliability, validity, and utility of instruments for self-report and informant report concerning symptoms of ADHD in adult patients. Journal of Attention Disorders. 2008; 11(4):445-458. [PubMed: 18083961]

Lahey BB, Applegate B, McBurnett K, Biederman J, Greenhill L, Hynd GW, Shaffer D. DMS-IV field trials for attention deficit hyperactivity disorder in children and adolescents. The American Journal of Psychiatry. 1994; 151(11):1673-1685. [PubMed: 7943460]

Lahey BB, Pelham WE, Loney J, Kipp H, Ehrhardt A, Lee SS, Massetti G. Three-year predictive validity of DSM-IV attention deficit hyperactivity disorder in children diagnosed at 4-6 years of age. American Journal of Psychiatry. 2004; 161(11):2014-2020. [PubMed: 15514401]

Lahey BB, Pelham WE, Schaughency EA, Atkins MS, et al. Dimensions and types of attention deficit disorder. Journal of the American Academy of Child and Adolescent Psychiatry. 1988; 27(3):330335. [PubMed: 3379015]

Leblanc N, Boivin M, Dionne G, Brendgen M, Vitaro F, Tremblay RE, Pérusse D. The development of hyperactive-impulsive behaviors during the preschool years: the predictive validity of parental assessments. Journal of Abnormal Child Psychology. 2008; 36(7):977-987. [PubMed: 18330688]

Marcus DK, Barry TD. Does attention-deficit/hyperactivity disorder have a dimensional latent structure? A taxometric anlaysis. Journal of Abnormal Psychology. 2011; 120(2):427-442. [PubMed: 20973595] 
Martel MM, von Eye A, Nigg JT. Developmental differences in structure of Attention-Deficit/ Hyperactivity Disorder between childhood and adulthood. International Journal of Behavioral Development. 2012; 36(4):279-292. [PubMed: 25635150]

Molina B, Sibley MH. The Case for Including Informant Reports in the Assessment of Adulthood ADHD. The ADHD Report. 2014; 22(8):1-7.

Olson, SL. Developmental perspectives. In: Sandberg, S., editor. Hyperactivity and attention disorders of childhood (2nd Ed.). Cambridge monographs in child and adolescent psychopathology. Cambridge: Cambridge University Press; 2002.

Opsahl T, Agneessens F, Skvoretz J. Node centrality in weighted networks: Generalizing degrees and shortest paths. Social Networks. 2010; 32(3):245-251.

Opsahl T, Panzarasa P. Clustering in weighted networks. Social Networks. 2009; 31:155-163.

Owens JS, Goldfine ME, Evangelista NM, Hoza B, Kaiser NM. A critical review of self-perceptions and the positive illusory bias in children with ADHD. Clinical child and family psychology review. 2007; 10(4):335-351. [PubMed: 17902055]

Pelham WE Jr, Fabiano GA, Massetti GM. Evidence-based assessment of attention deficit hyperactivity disorder in children and adolescents. Journal of Clinical Child and Adolescent Psychology. 2005; 34(3):449-476. [PubMed: 16026214]

Pillow DR, Pelham WE, Hoza B, Molina BSG, Stultz CH. Confirmatory factor analyses examining Attention Deficit Hyperactivity Disorder symptoms and other childhood disruptive behaviors. Journal of Abnormal Child Psychology. 1998; 26(4):293-309. [PubMed: 9700521]

Polanczyk G, de Lima MS, Horta BL, Biederman J, Rohde LA. The worldwide prevalence of ADHD: a systematic review and metaregression analysis. The American journal of psychiatry. 2007; 164(6):942-948. [PubMed: 17541055]

Power JD, Fair DA, Schlaggar BL, Petersen SE. The development of human functional brain networks. Neuron. 2010; 67(5):735-748. [PubMed: 20826306]

Puig-Antich, J.; Ryan, N. Kiddie Schedule for Affective Disorders and Schizophrenia. Pittsburgh, PA: Western Psychiatric Institute; 1986.

Shaffer D, Fisher P, Lucas CP, Dulcan MK, Schwab-Stone ME. NIMH Diagnostic Interview Schedule for Children Version IV (NIMH DISC-IV): description, differences from previous versions, and reliability of some common diagnoses. Journal of the American Academy of Child \& Adolescent Psychiatry. 2000; 39(1):28-38. [PubMed: 10638065]

Shaw P, Eckstrand K, Sharp W, Blumenthal J, Lerch JP, Greenstein D, Rapoport JL. Attention-deficit/ hyperactivity disorder is characterized by a delay in cortical maturation. Proceedings of the National Academy of Sciences. 2007; 104(49):19649-19654.

Sibley MH, Pelham WE, Molina BSG, Gnagy EM, Waxmonsky JG, Derefinko K, Wymbs B, Garefino A, Babinski DE, Kuriyan AB. When Diagnosing ADHD in young adults emphasize informant reports, DSM Items, and impairment. Journal of Consulting and Clinical Psychology. 2012; 80:1052-1061. [PubMed: 22774792]

Span SA, Earleywine M, Strybel TZ. Confirming the factor structure of Attention Deficit Hyperactivity Disorder symptoms in adult, nonclinical samples. Journal of Psychopathology and Behavioral Assessment. 2002; 24(2):129-136.

Sporns O, Chialvo DR, Kaiser M, Hilgetag CC. Organization, development and function of complex brain networks. Trends in cognitive sciences. 2004; 8(9):418-425. [PubMed: 15350243]

Sterba SK, Copeland W, Egger HL, Costello EJ, Erkanli A, Angold A. Longitudinal dimensionality of adolescent psychopathology: Testing the differentiation hypothesis. Journal of Child Psychology \& Psychiatry. 2010; 51(8):871-884. [PubMed: 20345843]

Stiles J, Moses P, Passarotti A, Dick FK, Buxton R. Exploring developmental change in the neural bases of higher cognitive functions: the promise of functional magnetic resonance imaging. Developmental neuropsychology. 2003; 24(2-3):641-668. [PubMed: 14561565]

Willcutt EG, Nigg JT, Pennington BF, Solanto MV, Rohde LA, Tannock R, Lahey BB. Validity of DSM-IV attention deficit/hyperactivity disorder symptom dimensions and subtypes. Journal of abnormal psychology. 2012; 121(4):991. [PubMed: 22612200]

Willoughby MT, Pek J, Greenberg MT. Family Life Project Investigators. Parent-reported attention deficit/hyperactivity symptomatology in preschool-aged children: factor structure, developmental 
change, and early risk factors. Journal of abnormal child psychology. 2012; 40(8):1301-1312. [PubMed: 22581375]

Wolraich ML, Lambert EW, Baumgaertel A, Garcia-Tornel S, et al. Teachers' screening for attention deficit/hyperactivity disorder: Comparing multinational samples on teacher ratings of ADHD.

Journal of Abnormal Child Psychology. 2003; 31(4):445-555. [PubMed: 12831232] 


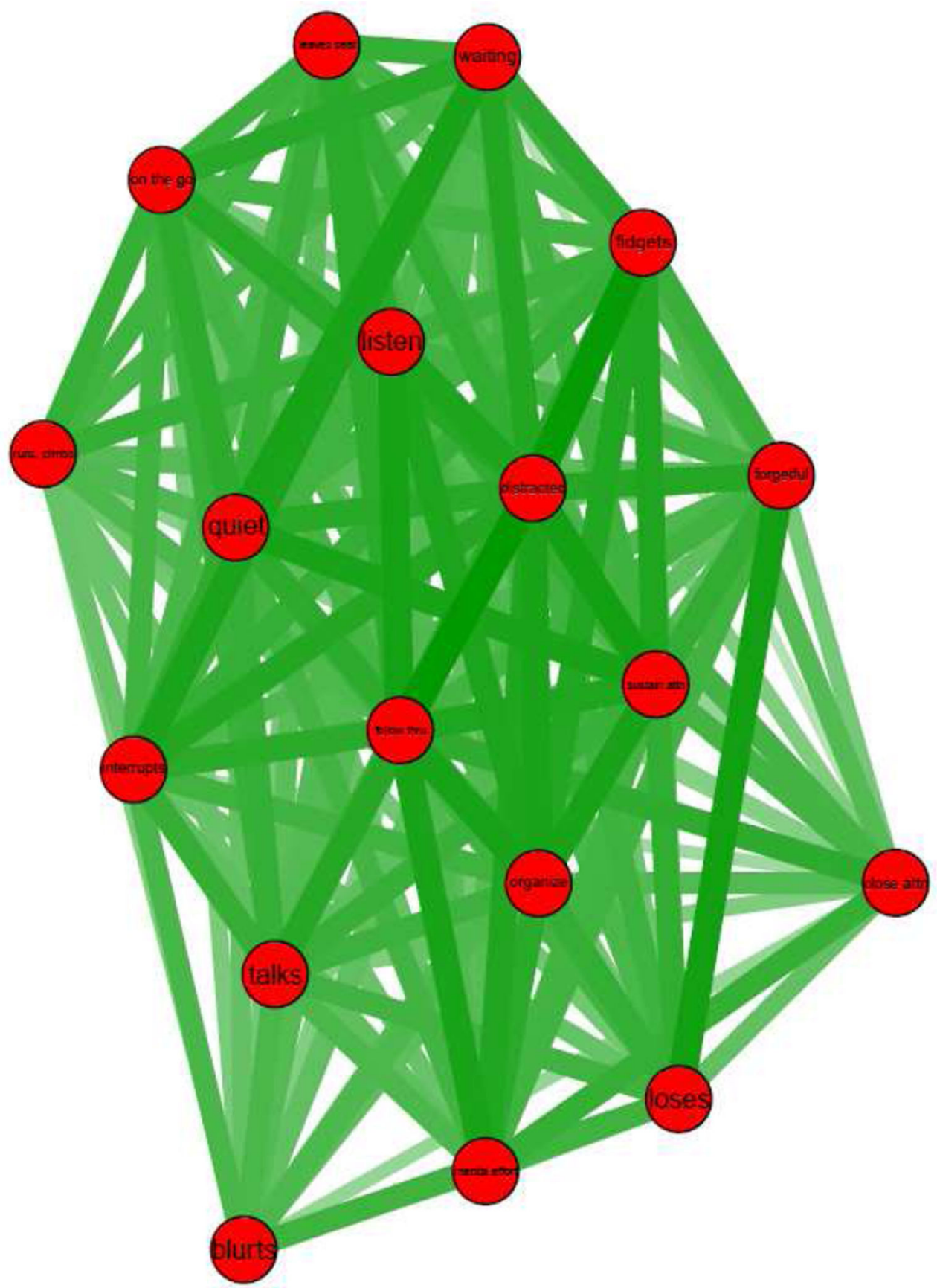

Figure 1. Visualization of One-Cluster ADHD Preschool Network

$\underline{\text { Symptom Key. }}$. Close attn=Often fails to give close attention to details or makes careless mistakes in schoolwork, at work, or during other activities. Sustain attn=Often has difficulty sustaining attention in tasks or play activities. Listen=Often does not seem to listen when spoken to directly. Follow thru=Often does not follow through on instructions and fails to finish schoolwork, chores, or duties in the workplace. Organize=Often has difficulty organizing tasks and activities. Mental effort=Often avoids, dislikes, or is reluctant to engage in tasks that require sustained mental effort. Loses=Often loses things necessary for tasks or activities. Distracted=Is often easily distracted by extraneous stimuli. Forgetful=Is often 
forgetful in daily activities. Fidgets=Often fidgets or raps hands or feet or squirms in seat. Leaves seat=Often leaves seat in situations when remaining seated is expected. Runs, climbs=Often runs about or climbs in situations where it is inappropriate. Quiet=Often unable to play or engage in leisure activities quietly. On the go=Is often "on the go," acting as if "driven by a motor." Talks=Often talks excessively. Blurts=Often blurts out an answer before a question has been completed. Waiting=Often has difficulty waiting his or her turn. Interrupts=Often interrupts or intrudes on others. 


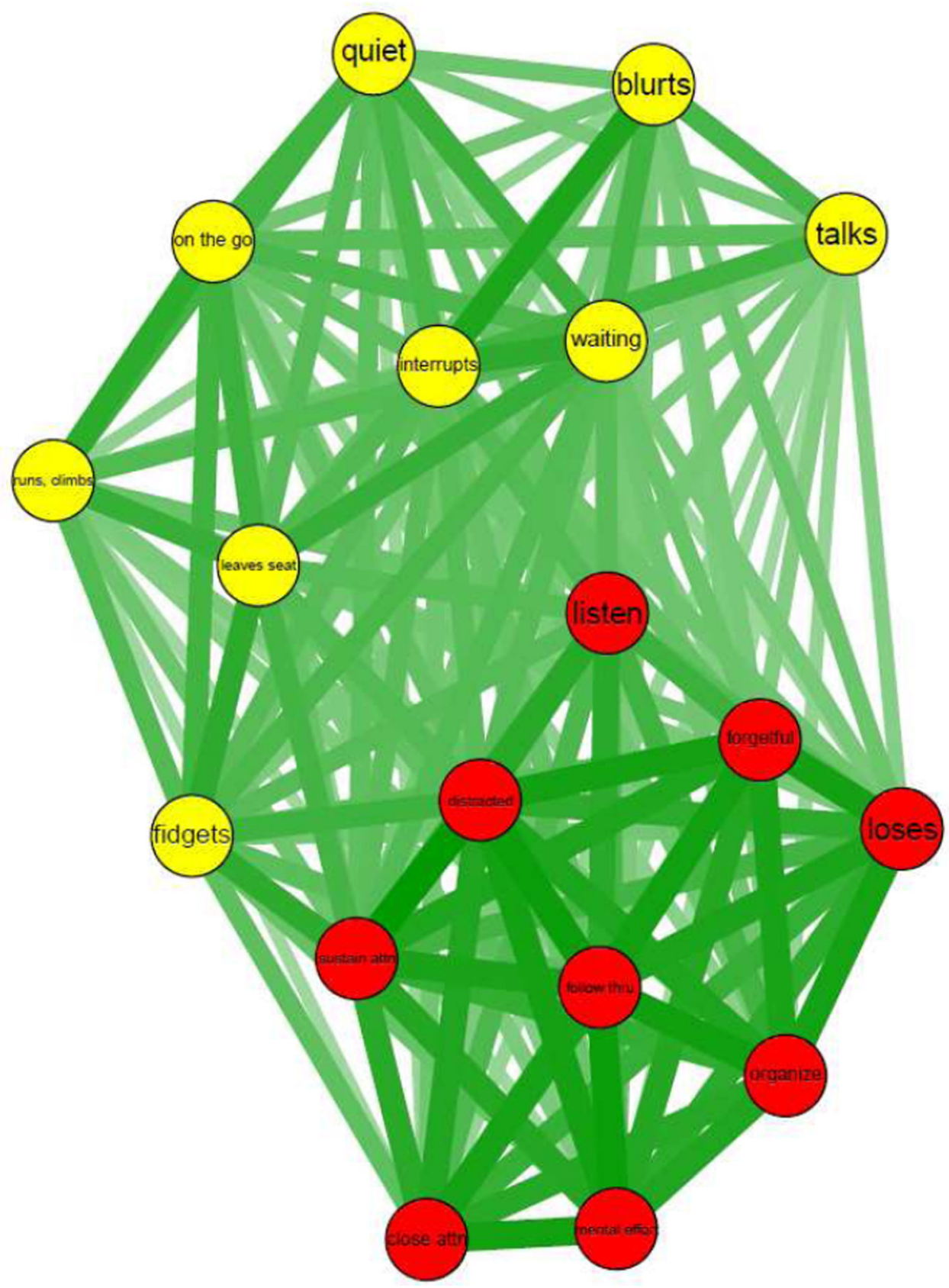

- inatt o hyperimp

Figure 2. Visualization of Two-Cluster Childhood Inattention and Hyperactivity-Impulsivity Network

Symptom Key. Close attn=Often fails to give close attention to details or makes careless mistakes in schoolwork, at work, or during other activities. Sustain attn=Often has difficulty sustaining attention in tasks or play activities. Listen=Often does not seem to listen when spoken to directly. Follow thru=Often does not follow through on instructions and fails to finish schoolwork, chores, or duties in the workplace. Organize=Often has difficulty organizing tasks and activities. Mental effort=Often avoids, dislikes, or is reluctant to engage in tasks that require sustained mental effort. Loses=Often loses things necessary for tasks or activities. Distracted=Is often easily distracted by extraneous stimuli. Forgetful=Is often 
forgetful in daily activities. Fidgets=Often fidgets or raps hands or feet or squirms in seat. Leaves seat=Often leaves seat in situations when remaining seated is expected. Runs, climbs=Often runs about or climbs in situations where it is inappropriate. Quiet=Often unable to play or engage in leisure activities quietly. On the go=Is often "on the go," acting as if "driven by a motor." Talks=Often talks excessively. Blurts=Often blurts out an answer before a question has been completed. Waiting=Often has difficulty waiting his or her turn. Interrupts=Often interrupts or intrudes on others. 


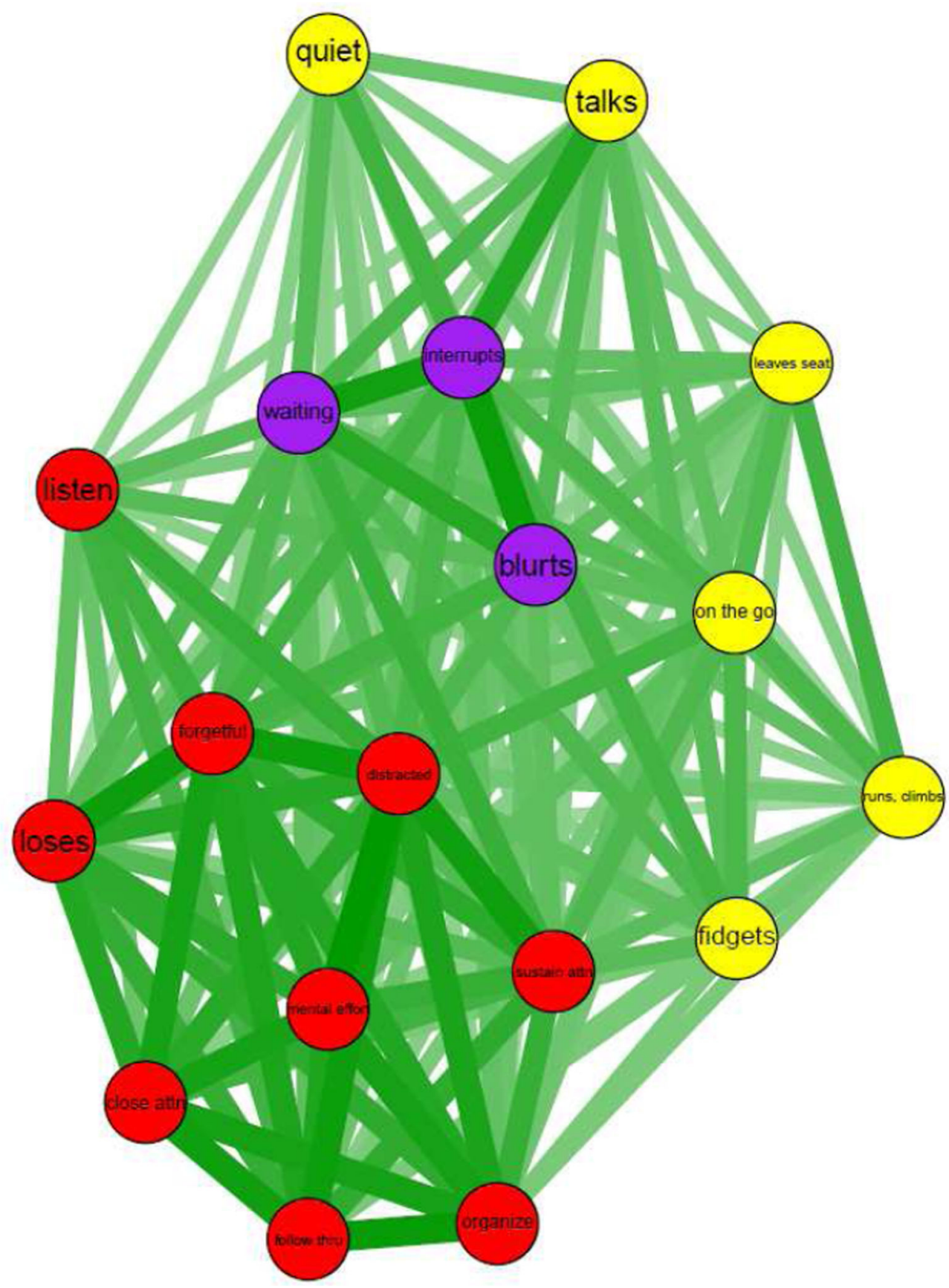

- inatt

Figure 3. Visualization of Three-Cluster Inattention, Hyperactivity, and Impulsivity Adolescent Network

Symptom Key. Close attn=Often fails to give close attention to details or makes careless mistakes in schoolwork, at work, or during other activities. Sustain attn=Often has difficulty sustaining attention in tasks or play activities. Listen=Often does not seem to listen when spoken to directly. Follow thru=Often does not follow through on instructions and fails to finish schoolwork, chores, or duties in the workplace. Organize=Often has difficulty organizing tasks and activities. Mental effort=Often avoids, dislikes, or is reluctant to engage in tasks that require sustained mental effort. Loses=Often loses things necessary for tasks or 
activities. Distracted=Is often easily distracted by extraneous stimuli. Forgetful=Is often forgetful in daily activities. Fidgets=Often fidgets or raps hands or feet or squirms in seat. Leaves seat=Often leaves seat in situations when remaining seated is expected. Runs, climbs=Often runs about or climbs in situations where it is inappropriate. Quiet=Often unable to play or engage in leisure activities quietly. On the go=Is often "on the go," acting as if "driven by a motor." Talks=Often talks excessively. Blurts=Often blurts out an answer before a question has been completed. Waiting=Often has difficulty waiting his or her turn. Interrupts=Often interrupts or intrudes on others. 


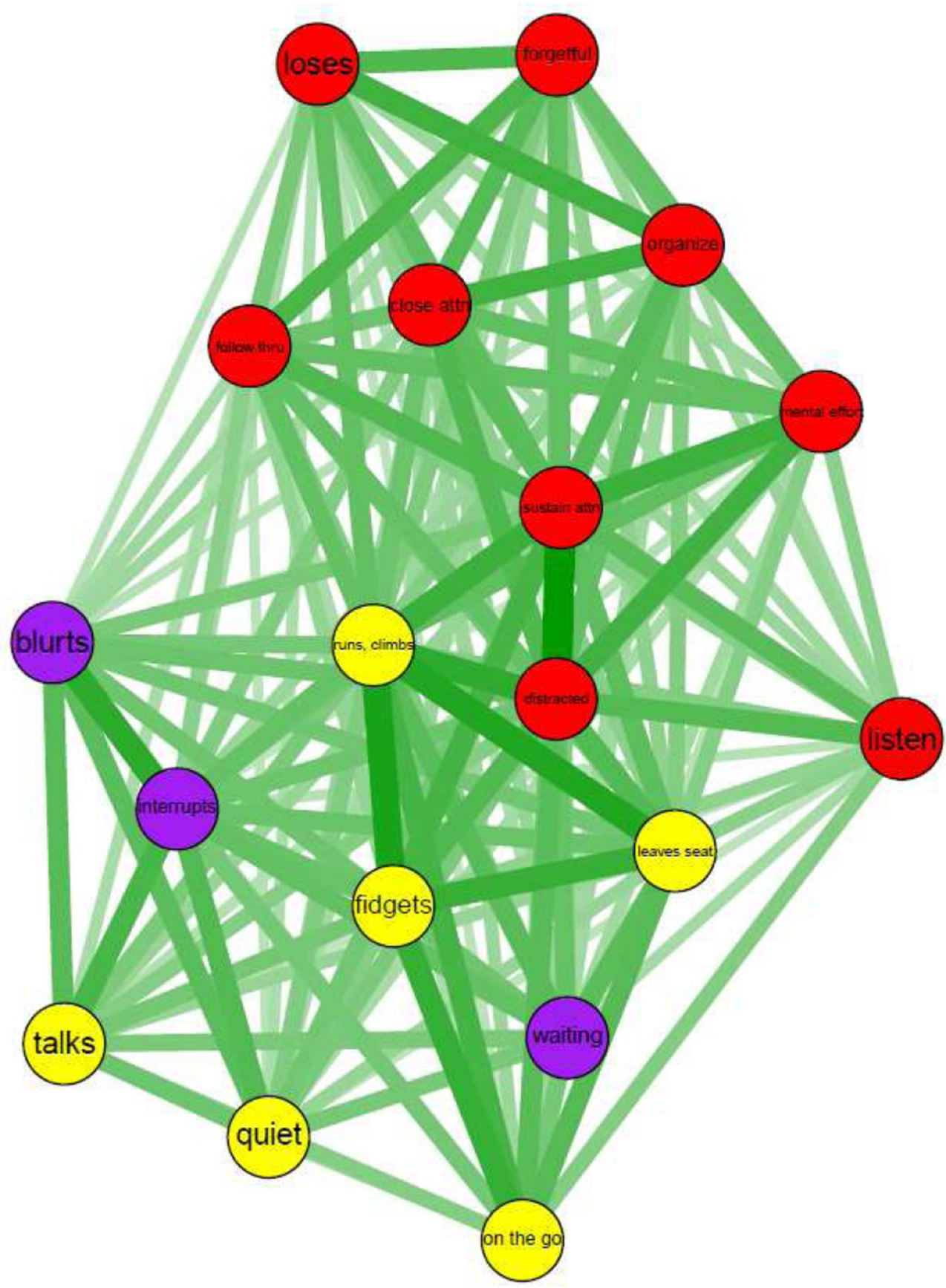

- inatt

Figure 4. Visualization of Three-Cluster Inattention, Hyperactivity, and Impulsivity Adult Network

Symptom Key. Close attn=Often fails to give close attention to details or makes careless mistakes in schoolwork, at work, or during other activities. Sustain attn=Often has difficulty sustaining attention in tasks or play activities. Listen=Often does not seem to listen when spoken to directly. Follow thru=Often does not follow through on instructions and fails to finish schoolwork, chores, or duties in the workplace. Organize=Often has difficulty organizing tasks and activities. Mental effort=Often avoids, dislikes, or is reluctant to engage in tasks that require sustained mental effort. Loses=Often loses things necessary for tasks or 
activities. Distracted=Is often easily distracted by extraneous stimuli. Forgetful=Is often forgetful in daily activities. Fidgets=Often fidgets or raps hands or feet or squirms in seat. Leaves seat=Often leaves seat in situations when remaining seated is expected. Runs, climbs=Often runs about or climbs in situations where it is inappropriate. Quiet=Often unable to play or engage in leisure activities quietly. On the go=Is often "on the go," acting as if "driven by a motor." Talks=Often talks excessively. Blurts=Often blurts out an answer before a question has been completed. Waiting=Often has difficulty waiting his or her turn. Interrupts=Often interrupts or intrudes on others. 